\title{
Subordinate Clauses of Condition with the Conjunction "If" in English and Their Equivalents in Azerbaijani Language
}

\author{
Leyla Nabiyeva $^{1}$ \\ ${ }^{1}$ Azerbaijan State University of Languages, Baku, Azerbaijan \\ Correspondence: Leyla Nabiyeva, Azerbaijan State University of Languages, Baku, Azerbaijan. E-mail: \\ leyla_nabiyeva@hotmail.com
}

Received: June 7, 2013 Accepted: July 4, 2014 Online Published: September 29, 2014

doi:10.5539/ass.v10n19p39 URL: http://dx.doi.org/10.5539/ass.v10n19p39

\begin{abstract}
Language is essential to understanding the social interaction of our lives, and sentences are the building blocks of a language. As a communicative and a nominative unit, sentences are always used to express any case, right moment which the speaker or writer wishes to express to the listener or reader.
\end{abstract}

Keywords: subordinate clauses of condition, English, Azerbaijani language

\section{Introduction}

Language is essential to understanding the social interaction of our lives, and sentences are the building blocks of a language. As a communicative and a nominative unit, sentences are always used to express any case, right moment which the speaker or writer wishes to express to the listener or reader.

In every language, a sentence has a specific word order. In the analysis of a language, studying the formation of this specific word order must take grammar and prosody into consideration. The difficulties involved in analyzing the sentence, whether in reference to the language system or not, has always worried linguists. As an example of this difficulty, the position of F. de Saussure, a father of 20th century linguistics wrote "... as far as the phrase is relevant to language? If it is directly related to the spoken act, it cannot act as a unit of language." This is no longer considered valid by modern linguists, who consider his concepts very incorrect because he arranged all syntagm types of sentences and referred them not to speech but to language.

In any case, to include the combinations of those units into one or another group is difficult because, in their organization, each factor appears so uncertain that it is difficult to distinguish them. This issue has created two conflicting approaches. One of these approaches belongs to E. Benveniste, another one to A. N. Chomsky. According to the first, with the help of sentences, we leave the language as a system of signs, and enter the world where there is an expression of speech, language which is a means of contact. The sentence refers to speech. It can be defined as follows: "Since the sentence is a segment of speech, it is a unit." According to A.N.Chomsky "Sentence is a unit of language." Along with considering the sentence structure units of a language, O. I. Moskalskaya considers that it has a complicated symbolic character on the level of nominative, cognitive, and communicative properties: ".... Modern semantic direction, along with discussing the communicative orientation of sentences, especially emphasizes its nominative aspect, treating them not as simple characters. The concept of lexeme a period after fact accepts the sentence as a complex symbol (sign), as a special nomination, unlike detonation, which claims only the subject, means the whole situation, and separate fact" By discussing "syntactic paradigm", N. Y. Şvedova understands the different ranks of the morphological expression of the predicate. In addition, V. V. Vinogradov considers the predicativeness, syntactic paradigms and the determinant the main features of the sentence. Comparing the English and Azerbaijani languages, examples of syntactic paradigms can be expressed as follows:

/The son learns// (Oğul öyrənir)

/The son learned// (Oğul öyrəndi)

/The son is learning// (Oğul öyrənməkdə davam edir).

In recent years, research on the syntax of the sentence is investigated from two aspects: 
- the planning of the expressions of sentences in its lexical and grammatical order, and a hierarchical series of words, and in a broad sense, intonation

- the semantic plan includes the following: nominative (propositional), nominative (predicative assessment) and communicative aspects.

The nominative plan means the possession of sentences nominative minimum (proposition), and the modal terms of semantic categories (assessment, aspect, and time category and personality). The nominative and modal plans together constitute the semantic structure of the sentence. The communicative plan of the sentence is organically linked with the modality.

The choice of language elements is predetermined mainly by the content of the proposition, its place in the speech. The transition from a proposition to sentence requires replacement of multi - members' links with binary links. Analysis of the sentence begins with the separation of the propositional group on the subject and the predicate group. One may raise the level of transition to be the multiple connections and, vice versa, decrease it according to the level of the other members of the 'extension' of the predicate - as primary proposition in terms of the conversion sentence.

As the science of linguistics developed, the definitions of what is a sentence greatly modified. An early definition by Sir Alan Gardiner, who studied Egyptian philology, is "A sentence is an utterance which makes communication as long as the speaker has intended to make before giving himself a rest." Leonard Bloomfield wrote: "the sentence is a structure of articulating which cannot be any part of a large structure." Bloomfield believed that all questions of semantics and meaning to be unanswerable and took a mechanical approach to logistics. However, his paradigm of Bloomfieldean linguistics was replaced, in turn, by Noam Chomsky's paradigm of generative grammar.

S. Potter notes that, "the sentence is more important than the word," while J. Ries states, "the sentence is grammatically formed expressing its value in relation to the reality of the smallest unit of speech". And according to S.D. Katsnelson a sentence is formed from individual words, morphemic compounds and propositions.

The total option for evaluating the sentence comes down to this: it must have a certain grammatical structure and carry a certain meaning or charge of sense. Nevertheless, what is the main characteristic feature of the sentence remains undisclosed until the end; however, there is no doubt that it exists.

In recent years, the attention of researchers was paid to the bilateral study of the issues of syntax of complex sentences in English and Azerbaijani languages. Among these issues there is an important feature of how a complex sentence as a unit of language behaves in respect to its individual components. At this stage of linguistics, i.e., the phase, when the basic concepts are clarified and studied, it is quite acceptable to have the existence of differences in the questions on the nature of the conjunction, which expresses subordination, and particularly conjunctions, which do not express insubordination in a complex sentence.

The component parts of complex sentences are evaluated as sentences in English linguistics. Of course, in this case there is a shortage of terminology used, since there is no communicative sense of secondary proposition. It acts as an integral part of a complex sentence. Even at the separation of the integral components of a non-subordinate secondary complex sentence, the early sequence of the secondary sentence either is vastly weakened or broken completely. On the other hand, the intonation contour, showing the syntactic relations in these sentences is specifically different from the intonation pattern, located in a whole sentence. As in the simple sentence, the complex sentence is also characterized by the communicative integrity that expresses tonal completeness.

We now turn to the primary focus of this paper, which is to examine an important kind of sentence using the conjunction "if" and similar words conveying this meaning in English and a comparison with a similar usage in the Azerbaijani language.

The conjunction "if" in English is multiform and connects objectives of a secondary sentence with the main clause. R.V. Zandvoort writes, "if the same objective secondary sentence expresses question, doubt, uncertainty, etc. then they are linking the main clause by conjunction "if" and "whether." For example, /I wonder if he'll come//. However, "if" is mostly involved in the creation of conditional secondary sentences.

Further R.V.Zandvoort writes: "clauses of condition began if, supposing, suppose (in the questions), in case, so that, so long as, negative secondary sentences starting with "if ...not" or "unless" such as the following examples: 
/If he should call, tell him I am not at home/

/I shall not go if you do not come with me//

/I shall not go unless you come with me//

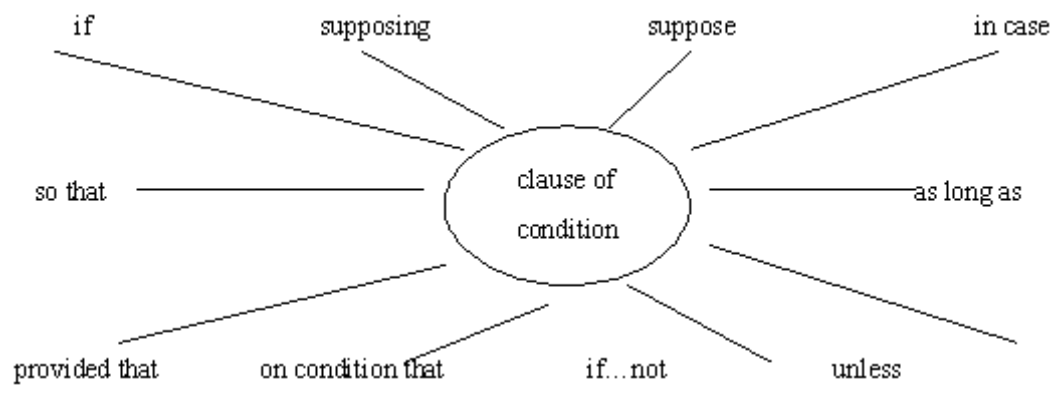

Figure 1.

Naming one an independent, and another dependent sentence, O. Musayev gives the following formula for the complex sentence: "Consisting from one main clause and one or more subordinate clauses is called a complex sentence". He distinguishes three main types of relations with subordinate clauses: with subordinate conjunctions, conjunctions and relative pronouns or adverbs and without conjunctions. By location, subordinate clause can be before and at the end of the main clause. The subordinate clause even can be in the middle of the main clause.

Here we would like to touch on the idea of O. Musayev about the role of intonation. The author writes: "When a subordinate clause stands after the main clause, they are both pronounced with a falling intonation. For example, /I was at home when he came //. Then he continues: "When a subordinate clause comes before the main clause, then the subordinate clause is pronounced with a rising tone and the main clause is pronounced with falling intonation". For example, /When he came I was at home//.

In fact, this interpretation does not clarify anything because, firstly, the author does not show sentence transcription; secondly, intonation contours of a syntactic whole depend neither on their lexical volumes, nor on the location of the lexical components in position pre- or post-position. Only thanks to the relationship of components in a complex sentence does intonation generally acquire completeness and create a strong relationship between the components and syntactic integrity, because its components act separately. However, if considered from the point of view of intonation, it does not represent an independence. The intonation integrity as a communicative unit belongs to a whole sentence.

The assertion by O. Musayev that the secondary sentence may stand in the middle, also is confused, because, in this case, the author talks about the comma, which is used as a separation of the components from each other. Unfortunately, although this conclusion was made on the basis of action of living speech, it refers to writing sources. Further, in discussing auxiliary propositions of adverbs, O. Musayev gives some reasons which do not widely cover the conditional auxiliary proposition. "The subordinate clause of condition is that clause which has the function of condition".

The main clause may come in any structural form of a simple sentence. In this regard, the most reasonable explanation is the one by R. V. Zandvoort about main and subordinate clauses. In cases of a double nuclei connection, which is created in groups of subject and conjugated (conjugation) verb, called an subordinate clause, the sentence itself is a compound sentence. For example, /When the authorities had arrived, the ceremony began// (Nə vaxt ki, rəhbər işçilər gəlib çatdı, mərasim başladı).

O. Musayev then proceeds to unions: "if, unless, suppose, on condition, providing, provided (that)." After all this he continues his thought: "When the subordinate clause of condition denotes unreal condition, the conjunction "if" can be omitted, in this case there is an inversion, i.e., a part of the predicate comes before the subject. For example, /Were I you, I should go to the country to work //.

In fact, "clause" may be assigned to both available components mentioned here. However, the first component, which is relatively free, is the main clause, the second component which is dependent is the subordinate clause. 
R.V. Zandvoort in his grammar points ten kinds of adverbial clauses and polysemy of some conjunctions. For example, "when" can link the subordinate clause of time and conditions, and "if," in its turn, can link as a conditional and the concessional subordinate clauses as well. Sometimes it is difficult to distinguish the adverbial clause of sentences for their meaning, for example, here include the sentences of time and concession with the conjunction "when", and the sentences of condition and adverb with the conjunction "if". The conjunction "if" can also be used in the subordinate clause of object.. For example: / I wonder if he'll come? //

R.V. Zandvoort writes that, if the sentences begins with "it" then the subordinate clause begins with "if" and "when." For example, / It would be most important if the Court came to another result //.

In modern English, "if" can act both as a noun and as a conjunction. According to the fictions "if" as a noun usually used in sentences only in plural. As the conjunction "if" has many variants and options of its usage,

Condition (Mary will go to university if she gets admission).

Every time (If I call her, she is always busy).

Exclamation (If that isn't the last problem!)

Granting (If that is true, what should Julie do?)

When or whenever (If it was snowing, we had to play inside).

Whether (John, ask if Alba plans to come to the concert).

Wish (If Sophia had only heard me sing!)

Information (Serena asked if I knew English).

Question (What will Anne do if John dies?).

A conditional clause of sentences denotes performing conditional action in the main clause and this type of sentence is associated with the main clause, using one of the following conjunctions "if, unless, suppose, on condition, providing, provided (that)". For example:

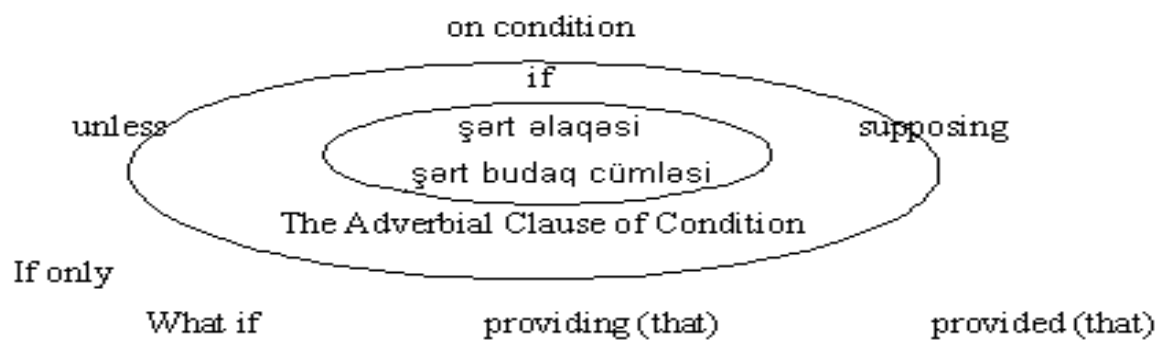

Figure 2 .

/Unless she wanted to hear the conversation below she wouldn't open the window//

/If I had power I would sink the sea beneath the earth//

Conditional subordinate clauses in English are primarily determined in three ways :

Option I: These kinds of subordinate clauses possibilities of action. Their structure is as follows:

$\begin{array}{ll}\text { If clause } & \text { Main clause } \\ \text { Verb in the present tense } & \text { Verb in the imperative } \\ \text { If you want to take a photo } & \text { press this button }\end{array}$

In a sentence of this type, if the predicate of the main clause can be used in the future tense, the subordinate verb sentences cannot express future time. For example, / If you work hard you will succeed//.

Option II: This type of sentence expresses unreality of action. The sentence has the following structure:

If clause

Simple past tense (subjunctive)

If she had wings
Main clause

Conditional tense (would do etc.)

she would fly 
Option III: This type of conditional subordinate sentence expresses support of those actions, the performance which in the distant past is not possible, and has the following structure:
If clause
Past Perfect Tense
If + past perfect
If she had been tall enough
Main clause
Perfect conditional
Should/would have done
she would have been recruited

Some linguists and grammarians consider that it is possible to use the "Zero Conditional" in the subordinate clause of condition in English language, for example, /If you drop sugar into water, it melts//; /If you throw a piece of wood in the sea, it floats//.

An interesting point in this regard is that the sentences of this type are used to express actions that are repeated, and in this case as an alternative, instead of "if," used "when:" /If you freeze water, it expands//; /When you freeze water, it expands//

Variability in the use of the subordinate clause of condition are primarily related to the time of the performed actions. For example, /If you liked tennis, we could go and play on the new courts// (Here with the modal verb "could", could may be used with the verbs "would" or "might"). The speaker does not report about the possibility of performance of acts in the past (despite the fact that the verb "liked" as used in the past tense), and emphasizes the fact that is understood, such as: /you like to play tennis (in the present tense), so it is not necessary to go to the new tennis court//.

To express the actions that can be done in the future, the "if" in clauses is used in the present tense, in the main clauses in the form of the future tense: /If the Bulls win the game tomorrow, they will be champions again.//

To express an unreal act in the present tense, the "if" in a clause is used in the form of past tense: /If they were available anywhere, I would pay any price for them.//; /If he were a good friend, he would buy them for me.//

For expressing unreal actions in the past tense, the "if" in a clause is preferred to be used in the past perfect tense: /If I had known you were coming, I would have baked a cake//; /If the Pacers had won, Aunt Gladys would have been rich.//

Regarding acts which may be done in the future, "if" is used in a clause in the present tense, in the main clause is used as the structure of "will" or "be going + main verb, such as :

I. If + present form + will, can or may /If I am late, I will call you//; /If you need me, you can call me at home//; /If you arrive earlier, you may have dinner//.

II. If + past form + would, could or might /If I got a pay rise, I would buy a new car//; /If you left your job, you could travel around the world//

III. If + past perfect + would/might/could have done /If I had revised, I would have passed my exams//; /If we had gone earlier, we might have got to the station on time//

Sentences with the conjunctions "if" in English language are the equivalent of subordinate clauses of condition in Azerbaijan language. However, sometimes it is difficult to determine the boundaries of conditional clauses and they may even be confused them with the subordinate clauses of object. For example, in Azerbaijani /no əkərsən/, onu da biçərsən/ is explains as a conditional clause. However, many linguists who study the frequency of use of such clauses, which would not have the "if" equivalent suffixes /sa-sə/, consider them to be conditional subordinate clauses.

In our material, there is a sentence in English: /If I should speak, she would mock me//. Both of its components express unreal action /Mən danışsaydım, q1z məni məsxərəyə qoyardi//. Rather, if a person at that time or for another objective reason could not talk, this condition has negated execution completing the action $(/ \ldots /$ she would mock me //).

A subordinate clause of condition, which expresses the conditional probability, desire and wish, is one of the main part of the syntactic paradigm. The conditional clauses linked to the main clause with the conjunctions ləgər, hərgah, madam ki, ki, isə (-sa/-sə/) and by the intonation,

a) /Ogər əkdiyim çiçəklər bitsə, gələn il çoxlu gülümüz olacaq//

b) /Okdiyim çiçəklər bitsə, gələn il çoxlu gülümüz olacaq//

c) /Okdiyim çiçəklər bitsə, onda gələn il çoxlu gülümüz olacaq//

ç) /əkdiyim çiçəklər bitdi, bitdi, bitmədi, günahkar mən deyiləm// 
d) /Ogər əkdiyim çiçəklər bitsə, mən adımı dəyişərəm//

The main object in the article is the subordinate clauses of condition with the conjunction "if" in English and their equivalents in Azerbaijani language. The subordinate clauses of condition are widely used in both languages. We determine the connections between these sentences. On this point we primarily base on the functional grammar, which is a leading direction in modern linguistics. The subordinate clause has no independent communicative meaning and it is a part of a complex sentence, which open the meaning of the word in the main clause. We show here that, the conjunction "if" is polysemy. It is used also in the formation of the subordinate clause of object. The complex sentences with the conjunction "if" are translated into Azerbaijani as the subordinate clauses of condition.

\section{Summary}

The article deals with the problem of status of a sentence and a lot of linguistic resources are investigated. Much attention is paid to its referring to the speech or to the language. The problem of compound sentence, its components and their links also investigated here. Examples are given on subordinate clauses of condition with conjunction "if" in English and their equivalents in Azerbaijani language.

\section{References}

Abdullayev, A. (1974). Complex sentences in Modern Azerbaijan Language.

Benveniste. E. (1974). General Linguistics.

Bloomfield, L. (1933). Language (p. 600). N.-York.

Chomsky, N. (1962). Syntactical structures.

Chomsky, N. (2006). Language and Thought.

De Sossure, F. (1977). Writings in general linguistics.

Gardiner, A. H. (1932). Theory of Speech and Language (p. 420). Oxford.

Katsnelson, S. D. (2001). Category of Language and Thinking.

Moskolskaya, O. I. (1976). Problems on systemic describe the syntax.

Musayev, O. (2007). Grammar of English Language.

Potter, S. (1984). Language (p. 207). London.

Ries, J. (1931). Was ist ein Satz. Beiträge zur Grundlegung der Syntax. Heft 3, Prague.

Shvedova, N. Y. (1970). Grammar of Modern Russian Language (p. 172).

Veysalli, F. Y. (2008, 2009). Bases of structural linguistics.

Veysalov, F. Y. (1970). Completeness intonation in Modern German Language.

Vinogradov, V. V. (1977). Grammar Russian Language (p. 160).

Yadigar, F. (n. d.). Introduction to German linguistics.

Yespersen, O. (1958). Phylosophy of Grammar.

Zandwoort, R.W. (1963). Handbook of English Grammar (p. 349). London.

\section{Copyrights}

Copyright for this article is retained by the author(s), with first publication rights granted to the journal.

This is an open-access article distributed under the terms and conditions of the Creative Commons Attribution license (http://creativecommons.org/licenses/by/3.0/). 